Verstrynge, E., Schueremans, L., Van Gemert, D. (2012). Creep and failure prediction of Diestian ferruginous sandstone: modelling and repair options. Construction \& Building Materials, 29, 149-157: 2012. Original article DOI: 10.1016/j.conbuildmat.2011.10.042

\title{
Creep and failure prediction of Diestian ferruginous sandstone: modelling and repair options
}

\author{
E. Verstrynge, L. Schueremans, D. Van Gemert \\ K.U.Leuven, Department of Civil Engineering, Kasteelpark Arenberg 40, 3001 Heverlee, \\ Belgium
}

\begin{abstract}
Diestian ferruginous sandstone is a brown-red, porous sandstone which has been used for the construction of numerous monumental buildings in Belgium. Urged by a number of collapses of monuments, a research program was set up which aims at characterising the sandstone's behaviour under monotonic and sustained loading. It was found that the sandstone has a low compressive strength with a large scatter on its mechanical properties and is very sensitive to time-dependent mechanical deterioration. A viscoelastic model with damage is used to model the sandstone's creep behaviour. The model takes into account damage accumulation at low stress levels. The model is calibrated on the results of experimental creep tests and used to simulate the time-dependent deformations of a collapsed bell tower. Finally, future prospects for the use of this sandstone and repair options are discussed. Keywords: ferruginous sandstone, masonry, time-dependent deformations, experimental research, modelling, repair options
\end{abstract}

Email addresses: els.verstrynge@bwk.kuleuven.be (E. Verstrynge), luc.schueremans@bwk. kuleuven. be (L. Schueremans), dionys.vangemert@bwk.kuleuven. be (D. Van Gemert) 


\section{Introduction}

Diestian ferruginous sandstone was frequently used for the construction of monumental buildings in the $14^{t h}-16^{\text {th }}$ century in Hageland, a region northeast of Brussels in Belgium [1]. The geological presence of the sandstone is situated around the city of Diest. The regions where the sandstone was used, correspond largely with the areas of local exploitation. However, at this moment, exploitation sites with good quality stone in adequate quantities are lacking and restorations are often carried out with debris material, which is recycled from other monuments. In the late $19^{\text {th }}$ and $20^{\text {th }}$ century, it was even common practice to replace damaged stone material with infill brickwork.

The sandstone contains iron fragments, which cause its typical brown-red colour. The iron compound, limonite, acts as a binder and the sandstone does not contain carbonate [2]. The sandstone has rather poor mechanical characteristics: it has a low overall compressive strength and there is a large scatter on these strength values. Additionally, the sandstone easily absorbs water, which reduces the strength even further. Monuments which were constructed with Diestian ferruginous sandstone have proven to be vulnerable for weathering influences and many show signs of deterioration and damage.

Although this work will focus on problems encountered when dealing with a particular type of ferruginous sandstone, the addressed issues, methods and conclusions can be extrapolated to many types of soft natural stone masonry.

\section{Mechanical characteristics of Diestian ferruginous sandstone}

The mechanical properties of Diestian ferruginous sandstone are largely scattered and depend on the amount of limonite, the sand and clay content, 
the porosity and the homogeneity of the sandstone. More ferruginous binder gives the stone a darker colour, which is an indication of higher strength [2]. The presence of larger amounts of clay has a negative influence on the strength value. Additional effects of weathering, biological and mechanical deterioration cause a time-dependent decrease of the strength properties.

In Fig. 1 and Fig. 2, a relation is indicated between both the density and pore volume with the compressive strength of six ferruginous sandstone samples which were tested during the experimental research, described in Section 3.1. The graphs also give an indication on the value and scatter of these characteristics.

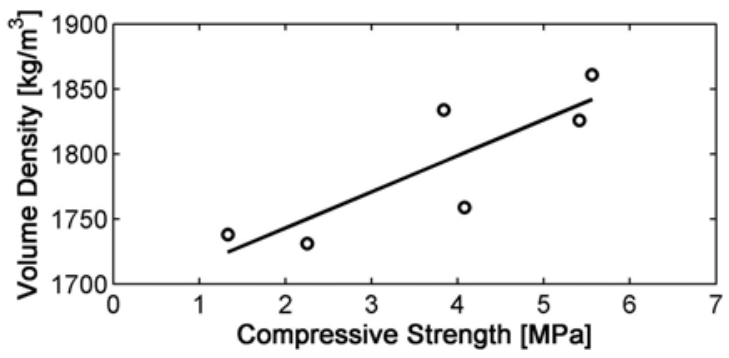

Figure 1: Relation between volume density and compressive strength of 6 Diestian ferruginous sandstone samples (compressive tests are described in Section 3.1)

Related to its qualities as a building material, the most pertinent problems which are encountered when dealing with Diestian ferruginous sandstone, are:

- The sandstone is vulnerable to weathering as it is soft and porous. Crusts are formed due to migration caused by water infiltration. After removal of the crust, a softer material layer is suddenly exposed to weathering influences, Fig. 3. 


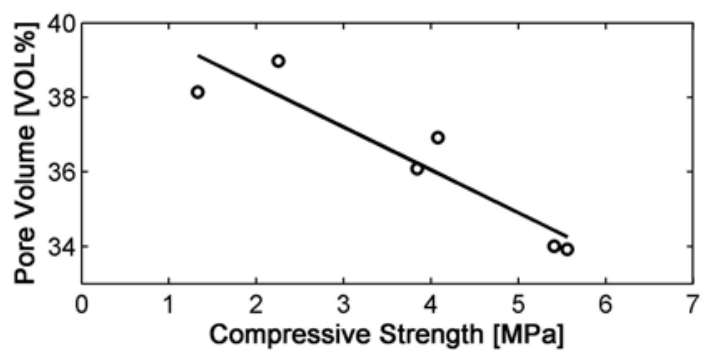

Figure 2: Relation between pore volume and compressive strength of 6 Diestian ferruginous sandstone samples (compressive tests are described in Section 3.1)

- A second, major issue is the low compressive strength of the masonry and the large scatter on these strength values. This makes the material vulnerable to creep effects and mechanical deterioration. Especially in taller structures, such as church towers and medieval city towers, the stress level at the base of the construction is high compared to the strength of the masonry.

- A specific problem, which can be categorised as biological deterioration, is the presence of bees which make their nest in the soft sandstone, decreasing the strength and coherence of the stone with a network of holes. In general, this phenomenon does not lead to large-scale problems.

- General problems which can be found in softer and porous stones, such as spalling due to freeze-thaw cycles and erosion by water and wind, are also present, Fig. 4.

In the research described below, the long-term damage accumulation which is caused by creep under high, sustained stress levels will be the main 
problem of interest. Two recent collapses of historical monuments, built with Diestian ferruginous sandstone, were attributed to time-dependent damage accumulation under high stress levels: the collapse of the bell tower of the Sint-Willibrordus church at Meldert and the partial collapse of the Medieval Maagden tower at Zichem. Both collapses occurred in 2006 [3]. Other examples of collapses, attributed to long-term creep damage can be found in $[4]$.

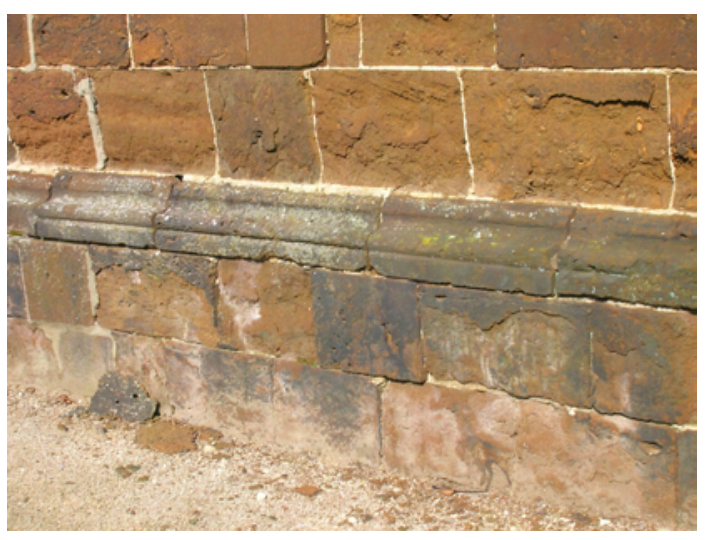

Figure 3: Formation of dark crusts at the surface of the sandstone. After the crust has fallen off, a weakened sandstone layer is exposed to environmental influences

\section{Experimental characterisation of material properties}

In this section, the mechanical properties of Diestian ferruginous sandstone will be discussed. Its behaviour under monotonic loading (compressive strength) and sustained loading (creep behaviour) are experimentally analysed. 


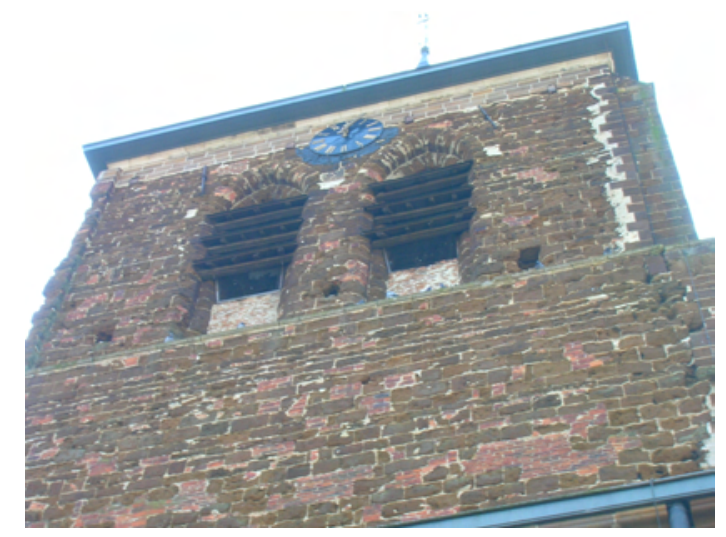

Figure 4: Bell tower of the Sint-Eustachius church at Zichem, Belgium. The outer layer of the masonry is in bad condition and partial repairs with brick infill and new or rectified sandstone blocks are visible

\subsection{Behaviour under monotonic loading: compressive strength}

Two separate test series were performed to measure the compressive strength of Diestian ferruginous sandstone. The first analysis concerned compressive tests on 14 samples obtained from debris material of the collapsed bell tower of the church at Meldert. From these specimens, 6 samples were selected for further testing of density and pore volume (see Fig. 1 and 2). The second analysis was performed on core samples, taken from the SintEustachius church at Zichem (33 specimens). All specimens were obtained through core drilling and have a cylindrical shape, with one of the following dimensions: diameter 113, 50 or $45 \mathrm{~mm}$, with a respective height of 100, 45 or $40 \mathrm{~mm}$, keeping the cross section to height ratio almost constant for the different dimensions.

A histogram of the results of all compressive tests on the samples from the two test series is presented in Fig. 5. No distinct difference is found 
between both test series. Since the scatter on the results is rather large, also no influence of the different specimen dimensions on the results is observed. The results are fitted with a normal and a lognormal distribution function to enable the calculation of a characteristic value, $f_{k}$, as indicated in the Eurocode [5]. The characteristic value is the compressive strength which is exceeded by $95 \%$ of the experimental results. The normal distribution function does not show a good fit to the experimental values. The characteristic value of the normal distribution $\left(f_{k, N}\right)$ is even negative and therefore physically impossible and not suited to be used for stability calculations. The lognormal distribution clearly shows a much better fit to the results and has been proven in literature to be adequate for modelling the low compressive strength values of masonry $[6,7,8]$. The mean compressive strength of the sandstone, according to the lognormal distribution function, $\left(f_{m, L N}\right)$ is $2.82 \mathrm{MPa}$ and the characteristic strength $\left(f_{k, L N}\right)$ is $0.77 \mathrm{MPa}$.

It can be concluded that the Diestian ferruginous sandstone has a very low compressive strength and a large scatter on the average strength value. This complicates stability calculations and strongly suggests the incorporation of this scatter in the analysis.

\subsection{Time-dependent behaviour}

To assess the long-term behaviour of Diestian ferruginous sandstone, a test program has been set up to obtain information on its behaviour under sustained loading. Therefore, test specimens were taken from the original material of the collapsed church tower at Meldert. The samples consist of ferruginous sandstone from the outer leaf, which was gathered after the collapse of the tower. Attempts were made to obtain samples for creep tests 


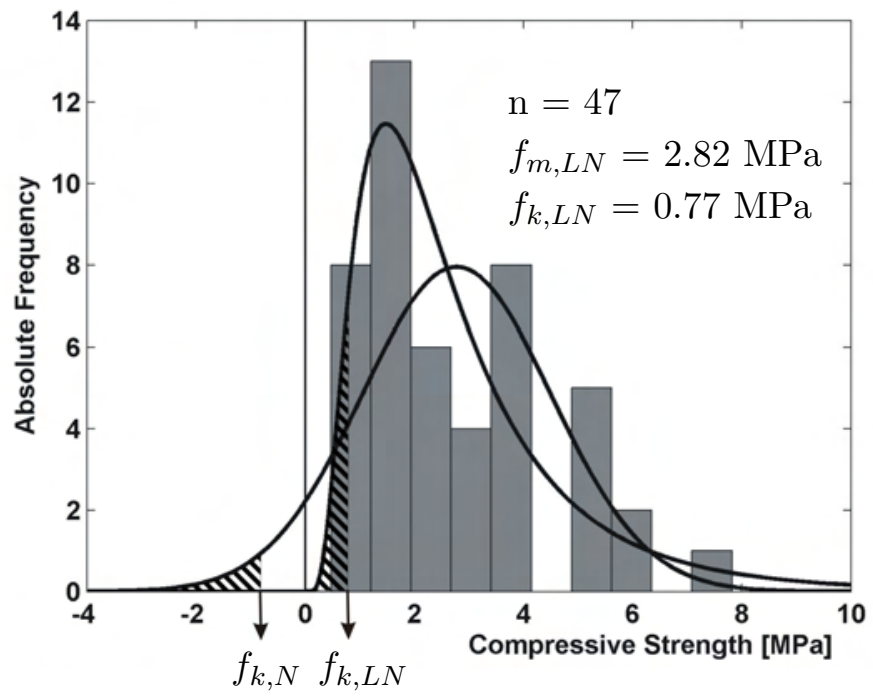

Figure 5: Histogram of experimental results of compressive tests (loading rate of 1 $\mathrm{mm} / \mathrm{min}$.) on Diestian ferruginous sandstone, together with normal and lognormal distribution function and indication of characteristic strength $f_{k}$

from the inner rubble core of the masonry, but this was not possible due to the low coherence of the masonry and bad quality of the lime mortar. Although the used samples consisted solely of ferruginous sandstone, they exhibited considerable creep during the tests. Due to the relatively large size of the sandstone blocks, compared to the rather thin mortar joints, the stone behaviour is considered to be representative for the overall behaviour of the outer leaf masonry. It should however be clear that tests on the composite material (sandstone and mortar) are necessary to obtain a full description of the masonry's behaviour.

A total amount of nine Cyclic Accelerated Creep Tests (CACT) have been performed. One preliminary test was performed on a sandstone specimen 


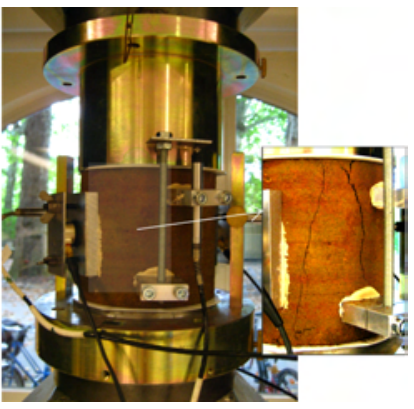

(a)

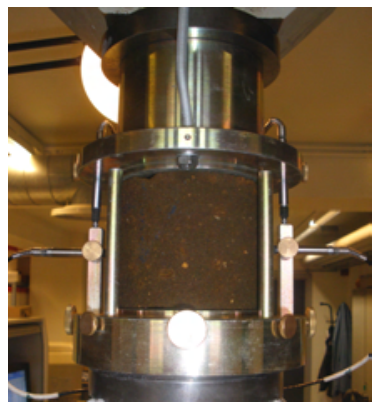

(b)

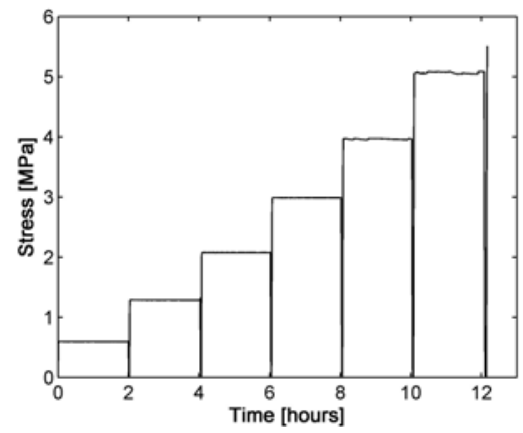

(c)

Figure 6: Preliminary setup (a), adapted setup (b) and loading scheme (c) of Cyclic Accelerated Creep Tests (CACT) on ferruginous sandstone specimens.

from the church at Zichem (Fig. 6a). The other eight tests were performed on specimens from the collapsed church at Meldert, as described above (Fig. 6b). The tests were performed on cylindrical sandstone samples with a diameter of $113 \mathrm{~mm}$ and height of $100 \mathrm{~mm}$. They were carried out on a hydraulic press with limited loading capacity $(100 \mathrm{kN})$ as the sample size and strength was limited. As the loading path could not be programmed to run automatically on this system, it was decided to perform cyclic tests and unload the specimen before each stress increase. This simplifies the interruption of the test, for example during the night. The loading scheme of the Cyclic Accelerated Creep Tests is indicated in Fig. 6c. This type of cycling step by step tests was proposed by Binda and Anzani to assess the creep behaviour of masonry prisms $[9,10]$.

In Fig. 6a, the setup of the preliminary creep test is presented. The vertical LVDTs (Linear Variable Differential Transformer) were glued on the side of the specimen to exclude deformations of the rough contact surface, 
but the glued connection was not efficient and the LVDTs were attached to the metal frame in further tests (see Fig. 6b). Fig. 6a and the small inset picture were taken with a time interval of 2.5 hours, in the same loading step, before and after the occurrence of creep damage.

The result of this preliminary cyclic accelerated creep test is presented in Fig. 7a and the result of a test in which more load steps were applied and the sandstone specimen failed during stress increase is presented in Fig. 7b. In Fig. 7a and b, the stress-strain diagram is presented, together with straintime evolution for each constant stress interval. The strain rate increases for subsequent stress levels. Each step shows two phases of the typical threephase creep curve (see Fig. 8, [11]); after stress increase, a primary phase with decreasing strain rate $(\mathrm{A})$ is observed and slowly, this strain rate evolves to a constant value and a constant slope is observed during the secondary creep phase (B). If the specimen does not fail during the stress increase, also the tertiary creep phase with increasing strain rate $(\mathrm{C})$ can be observed during the last loading step. Unfortunately, most specimens failed during the stress increase, as the time steps had a restricted duration to limit the execution time of one test. Only in the preliminary test, the stress level was kept constant during a period of three hours, in further tests, this time interval was restricted to two hours. Horizontal and vertical strain evolutions of all eight specimens from Meldert are shown in light grey in Fig. 10. The horizontal strains remain restricted until the last loading step and thus, failure dilatation only occurred at the very end of the creep tests. 


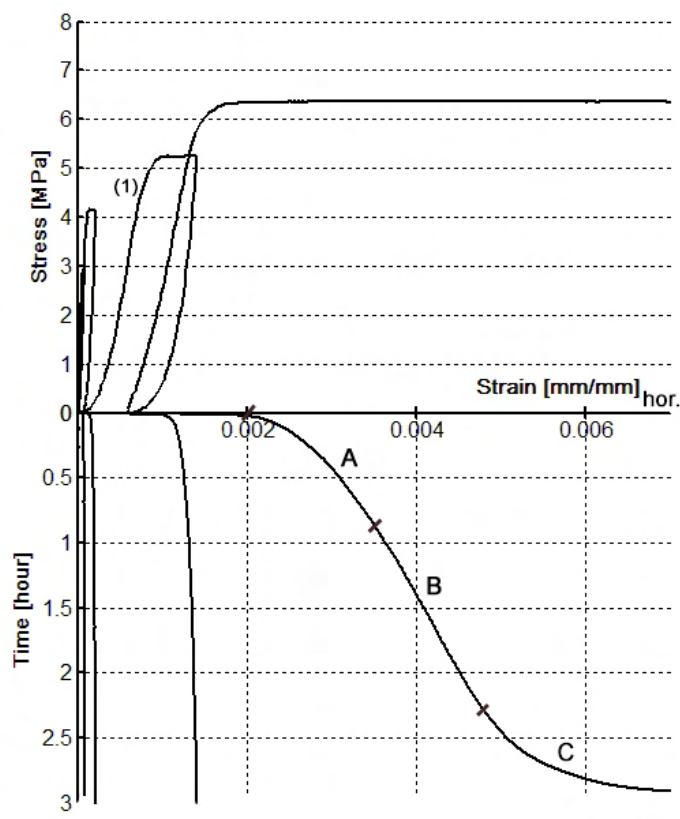

(a)

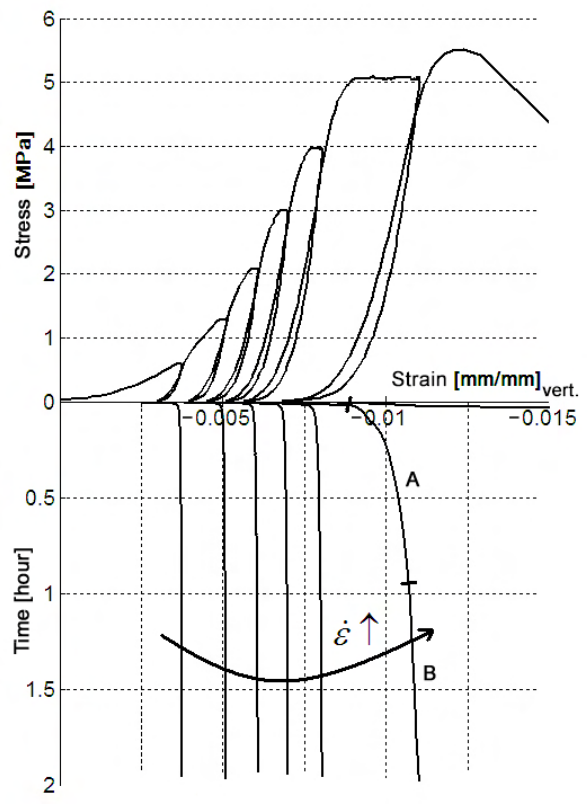

(b)

Figure 7: Stress-strain and strain-time evolution of CACT on sandstone specimen, with indication of primary (A), secondary (B) and tertiary (C) creep phase. In (b) the last loading step is not indicated as the specimen failed during stress increase. Lateral strains are presented for test (a) and axial strains for test (b) 


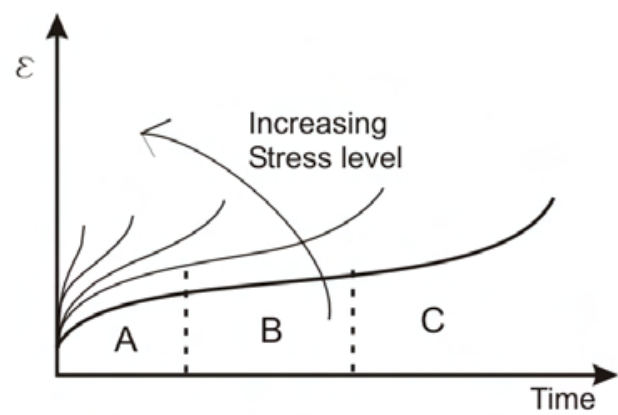

Figure 8: Typical three-phase creep curve with indication of primary (A), secondary (B) and tertiary $(\mathrm{C})$ creep phase

\section{Viscoelastic modelling}

To model the time-dependent behaviour of ferruginous sandstone, a viscoelastic model with damage is used. The model is based on a Burgers model with damage, see Fig. 9 [12, 13, 14]. The Kelvin component describes the primary creep phase with decreasing strain rate. The spring of the Maxwell component describes the elastic deformations and the dashpot the viscous secondary creep phase. The tertiary creep phase with increasing strain rate is modelled with a viscous damage parameter, $D^{V}$. This damage parameter has a dual formulation: firstly, it increases according to a damage rate formulation to describe strain increase under constant stress and secondly, its initial value depends on the relative stress level, to make the slope of the secondary creep phase dependent on the stress level [15]. The relative stress level, $\sigma^{*}$, is the ratio between the absolute stress, $\sigma$, and the average compressive strength, $f_{c}$, of the considered masonry.

If it is assumed that a constant stress is applied at $t=0$ and all internal variables remain constant in time, the differential equations of the Burg- 


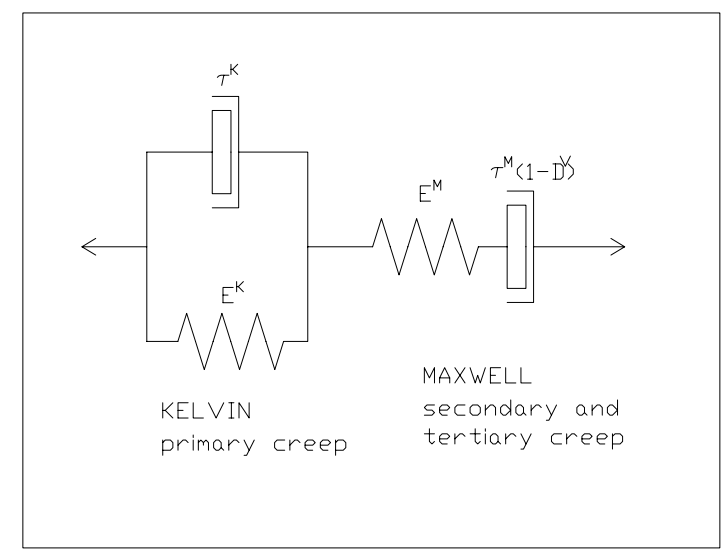

Figure 9: Schematic representation of the one-dimensional Burgers model with damage

ers model can be integrated in a closed-form, one-dimensional constitutive formulation [13]:

$$
\begin{aligned}
\varepsilon(\sigma, t) & =\frac{\sigma}{E^{M}}+\frac{t}{E^{M} \tau^{M}\left(1-D^{V}\right)} \sigma \\
& +\frac{1}{E^{K}}\left(1-\exp \left(\frac{-t}{\tau^{K}}\right)\right) \sigma
\end{aligned}
$$

Where $E^{K / M}$ is the Kelvin $(K)$ or Maxwell $(M)$ elastic modulus, $\tau^{K / M}$ the Kelvin or Maxwell time constant and $D^{V}$ the viscous damage parameter.

If the stress or internal variables do not remain constant during the considered time interval, the differential constitutive equations are integrated by assuming the internal variables to remain constant within a small time increment. If a time increment $\Delta t_{i}=t_{i}-t_{i-1}$ is considered, the differential equations can be integrated in closed form using a backward Euler scheme, as presented in previous work [15]. 
The model variables, which were calculated from the creep tests, are indicated in Table 1. Large scatter is found on the results, the Coefficient Of Variation (COV) is $55 \%$ for the compressive strength and $43 \%$ for the Young's modulus. A low characteristic strength of $f_{k}=1.17 \mathrm{MPa}$ is obtained according to the lognormal distribution.

As the number of creep tests was limited and especially the amount of tests which exhibited a tertiary creep phase was restricted, a number of the variables listed in Table $1\left(f_{t}, E^{K}, c, n\right)$ is based on the results of a former extensive research program which included different types of creep tests on low-strength masonry samples with lime mortar [15].

In Fig. 10, the creep model is used to simulate the experimental results. Vertical strains are indicated negative. The input values for the model variables were calculated as the average values of all tests. Therefore, the model indicates the "average" creep behaviour and deviations on this behaviour can be incorporated in the analysis as the scatter on the input variables is known. This is illustrated with the dotted lines in Fig. 10, which are model simulations made with the 0.05 and 0.95 quantile values of the compressive strength, $f_{c}$, and the Young's modulus, $E^{M}$. The compressive strength largely influences the time to failure, while the Young's modulus has a major influence on the strain prediction.

From the experimental results, it is found that creep damage accumulation during the secondary creep phase is present from relative stress levels of $40 \%$ for Diestian ferruginous sandstone, which is in line with results from previous creep test programs. An initiation level for viscous damage of $45 \%$ of the compressive strength was found for low-strength masonry with lime 
Table 1: Overview of model variables for Diestian ferruginous sandstone, calculated from the experimental data

\begin{tabular}{lcccl}
\hline model parameter & description & mean (st. dev.) & exp. data \\
\hline \hline$f_{c}[\mathrm{MPa}]$ & & compressive strength & $3.07(1.69)$ & compr. \\
\hline$f_{t}[\mathrm{MPa}]$ & & tensile strength & $0.3(0.1)$ & prev. \\
\hline$\nu[-]$ & Poisson ratio & $0.19(0.06)$ & compr. \\
\hline$\tau^{K}[\mathrm{~s}]$ & & Kelvin time constant & $20969(9741)$ & CACT \\
\hline$E^{K}[\mathrm{MPa}]$ & & Kelvin elast. modulus & $1500(300)$ & prev. \\
\hline$\tau^{M}[\mathrm{~s}]$ & $T_{m_{\_} a}$ & Maxwell time constant & $1500(200)$ & prev. \\
& $T_{m \_b}$ & $\left(\tau^{M}(t)=T_{m \_a} \cdot t^{0.7}+T_{m \_b}\right)$ & $448733(299686)$ & CACT \\
\hline$E^{M}[\mathrm{MPa}]$ & & Maxwell elast. modulus & $467(201)$ & compr. \\
\hline$D^{V}[-]$ & $A$ & viscous damage & $0.86(0.22)$ & CACT \\
& $B$ & $\left(D^{V}=A \sigma^{*}+B\right)$ & $-0.34(0.25)$ & CACT \\
& $c$ & $\left(\dot{D}^{V}=c\left(\frac{\sigma^{*}}{1-D^{V}}\right)^{n}\right)$ & $8.5 \mathrm{e}-11(1 \mathrm{e}-11)$ & prev. \\
& $n$ & & $8(1.2)$ & prev. \\
\hline \hline
\end{tabular}

Comments: The last column indicates which data were used for the calculation: compr. $=$ compressive tests on sandstone from Meldert CACT $=$ Cyclic Accelerated Creep Tests on sandstone from Meldert prev. $=$ results from previous research program [15]

mortar and 60-70 \% for masonry with hydraulic lime mortar, hybrid limecement mortar or low-strength cement mortar [11]. In literature, a stress level of $41 \%$ of the compressive strength has been found to induce secondary creep in brick masonry specimens which were taken from the collapsed tower of Pavia [4]. 


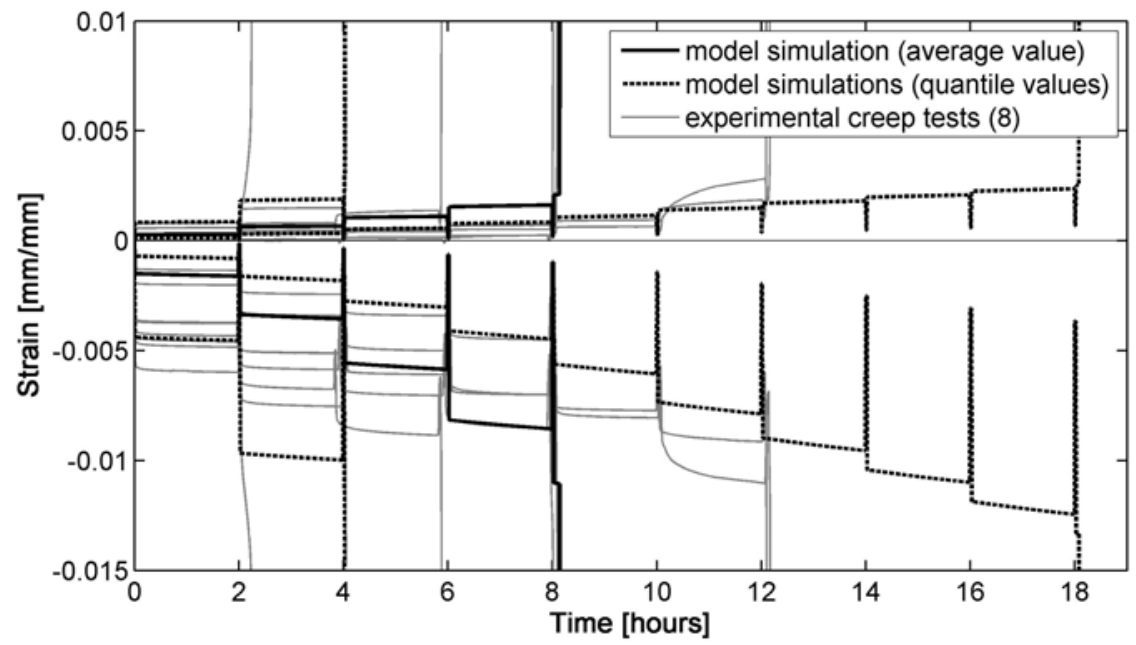

Figure 10: Experimental results and simulation of CACT on ferruginous sandstone. Dotted lines indicate the upper and lower bounds of the simulation, made with the $5 \%$ and $95 \%$ quantile values of model variables $f_{c}$ and $E^{M}$

\subsection{D finite element model}

To implement the time-dependent constitutive relations in a finite element code, the model was extended to a three-dimensional version [16]. Hereby, a non-rotating smeared crack model was assumed and a simple criterion is included to allow for the effect of triaxial stress state, as proposed by Bažant [17]. The biaxial failure envelope is defined by linear connections between the uniaxial compression and tension failures, Fig. 11. In the formulation proposed, the compressive or tensile strength in a certain direction increases or decreases if the transversal stresses have a positive or negative effect on the damage onset and growth in that particular direction. In the creep model, the adapted strength values are used in the description of the damage evolution, which depends on the relative stress ratio. 


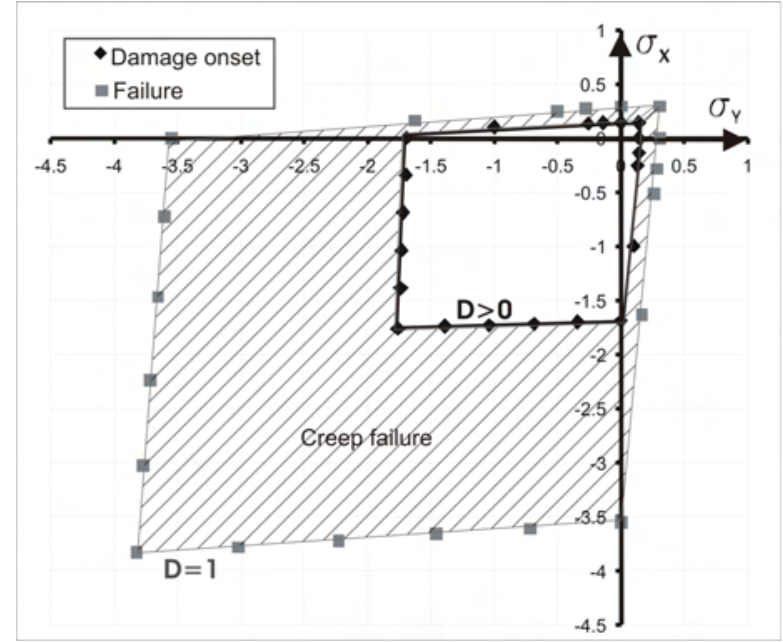

Figure 11: Biaxial failure envelope, with criterion for damage initiation and for failure under loading with high loading rate. The hatched area indicates creep failure

Mesh-dependency is present in the creep model due to the sensitivity of the simulation result on stress concentrations. These localised, high stresses trigger damage initiation and growth. This dependency was solved by using non-local state variables for the description of damage progress [16]. Different quantities can be averaged to adapt them to a non-local formulation: the damage energy release rate, the local damage itself [18], the local strains [19], the amount of plastic flow [20]. In the applied creep model, a nonlocal stress concept is used to calculate the damage progress. The simplest form is taken for the weighting function, $g$, which sets $g=1$ inside the representative volume and $g=0$ outside this boundary. This has the effect of an arithmetic averaging of the local stresses in the Gauss points within the finite domain of the representative volume, which is a sphere with a diameter equal to a characteristic length. The characteristic length represents a material property, and is assumed to be of the same order of magnitude as 
the maximum size of the material inhomogeneities [18].

The three-dimensional creep model is implemented in the finite element software Diana (TNO DIANA, release 9.3) and is applied in the next section to model the time-dependent behaviour of the bell tower of the church at Meldert. For a more detailed description of the model and its constitutive relations, the reader is referred to $[11,16]$.

\section{Application}

In this analysis, the data for ferruginous sandstone, as given in Table 1, are used to model the long-term behaviour of the bell tower of the church at Meldert, which collapsed in 2006 (see Section 1). The influence of three-leaf masonry or cyclic loading will not be included in this analysis.

To take into account the extremely large spread on the strength characteristics, the characteristic value of the compressive strength, $f_{k}=1.17 \mathrm{MPa}$, will be used during the analysis instead of the average compressive strength. A more elaborate manner of incorporating this scatter would be to apply techniques of spatial variability. These techniques could be incorporated in future research.

The 3D model of the bell tower is presented in Fig. 13. The upper part of the tower is omitted and replaced by an equivalent surface pressure on top of the tower. Symmetry is taken into account as only half of the tower was modelled, resulting in a total of 1600 elements. A radius of $500 \mathrm{~mm}$ is used for the averaging procedure to calculate the non-local damage. The tower is modelled in the situation which was present during the collapse, which means that a large opening is present at the rear side of the tower and a 
Table 2: Dimensions of bell tower and weight of sandstone, as used in the finite element model

\begin{tabular}{lc}
\hline height of tower (without spire) & $16 \mathrm{~m}$ \\
wall thickness (top - base) & $0.85-1.12 \mathrm{~m}$ \\
area of cross section at tower base & $14.6 \mathrm{~m}^{2}$ \\
density of sandstone & $1900 \mathrm{~kg} / \mathrm{m}^{3}$ \\
\hline
\end{tabular}

concrete beam is used to conduct the weight to the corner pillars. A plan and picture of the tower are presented in Fig. 12 and the dimensions of the tower are indicated in Table 2.

The average stress at the base, caused by the self-weight of the tower, is calculated to be $0.35 \mathrm{MPa}$. Fig. 13a presents the axial stresses which are present in the base of the tower. The stress in the corner pillars is increased up to 0.5-0.6 MPa due to the enlarged opening at the rear side. Small amounts of creep damage are present in these pillars.

Fig. 13b presents the vertical component of the viscous damage parameter. The small amounts of creep damage, introduced in the tower base by the simulation, do not cause failure. From the finite element calculations, it can be concluded that creep damage was present in the bell tower, but the amount of damage does not lead to failure due to the possibility of stress redistributions (towards the side walls of the tower) and the overall low amount of damage which does not cause unstable damage accumulation. However, little variations on the strength or model variables could initiate larger creep damage and failure.

It should be remarked that a number of important effects (three-leaf masonry, cyclic loading, moisture, scatter on model variables) were not included 


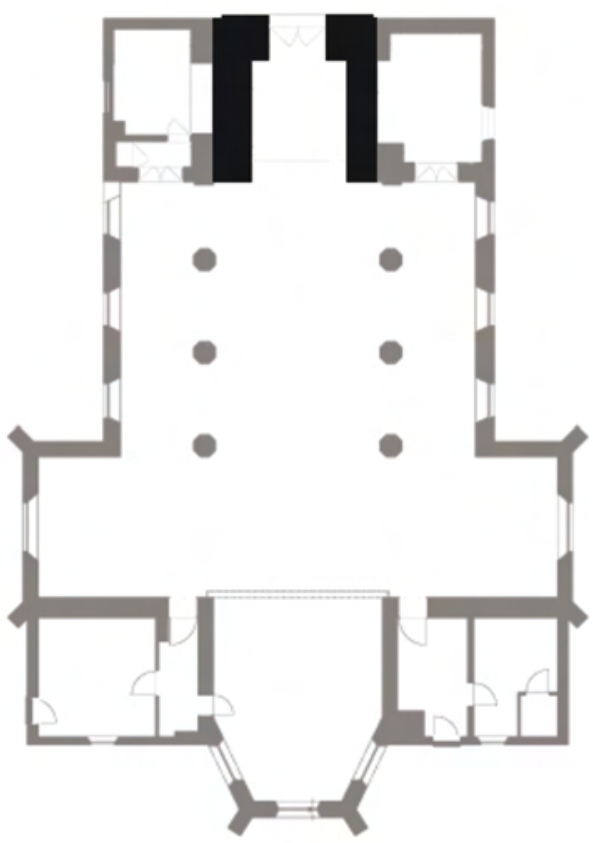

(a)

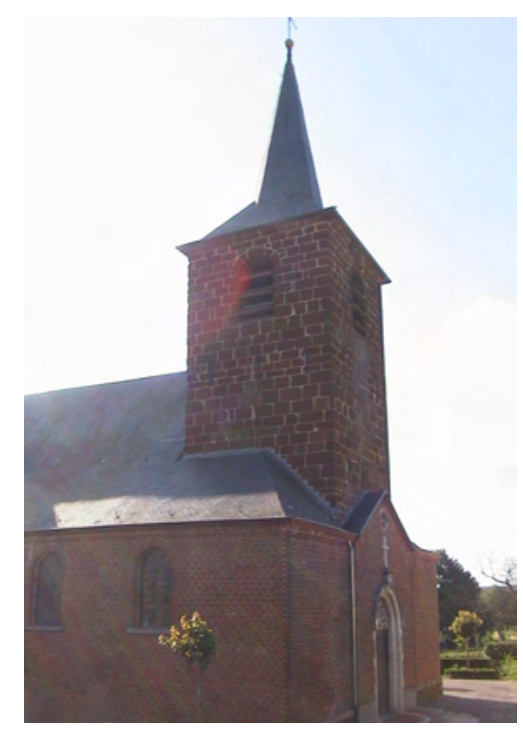

(b)

Figure 12: ground floor plan of Sint-Willibrordus church at Meldert with indication of tower base (a) and picture of tower before collapse (b)

in the analysis. Secondly, stress redistributions, which take place during the simulation, could be obstructed by a lack of inner cohesion of the walls. In this particular case, the temporarily removal of sandstone blocks from the outer leaf for rectification purposes could have decreased the cohesion of the wall, which was not included in this analysis. It should therefore be remarked that the presented finite element analysis only covers the average behaviour of the masonry.

The church tower was built as three-leaf masonry and therefore, important 


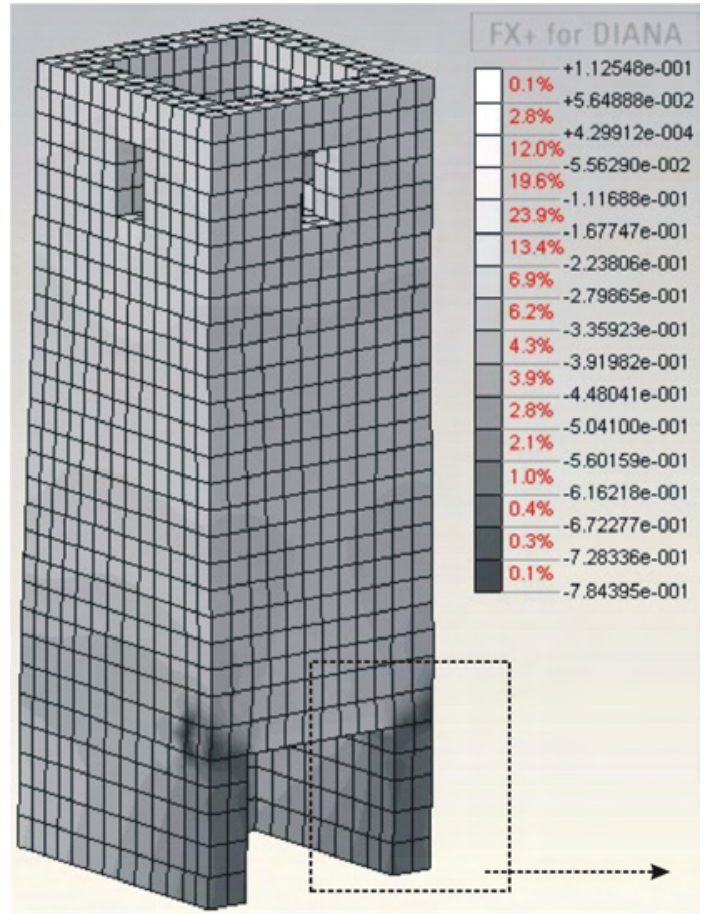

(a)

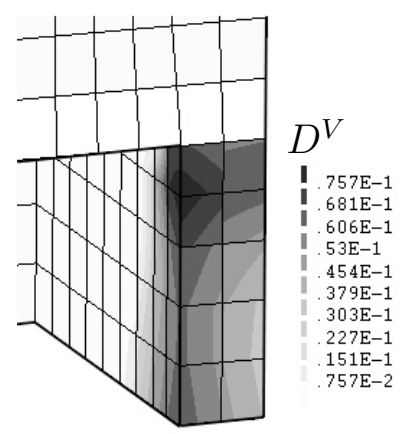

(b)

Figure 13: Contour plots of axial stresses (a) and vertical component of the viscous damage (b) in the bell tower of the church at Meldert 
stress redistributions can be expected. Although the outer leaf and the inner core were both constructed of Diestian sandstone and lime mortar, the inner core is assumed to be weaker, both in terms of strength and stiffness, as it was constructed as rubble masonry with irregular sandstone chunks and large amounts of lime mortar. In [16], it was analysed how the difference in strength and stiffness between the different leaves of three-leaf masonry can cause stress redistributions and increase creep damage accumulation.

The presence of creep damage in the base of the tower indicates a potentially dangerous situation, taken into account the lack of inner cohesion of the walls, which was proven by the collapse of the tower on $6^{\text {th }}$ July 2006 . The base of the tower failed and caused overturning of the tower, see Fig. 14.

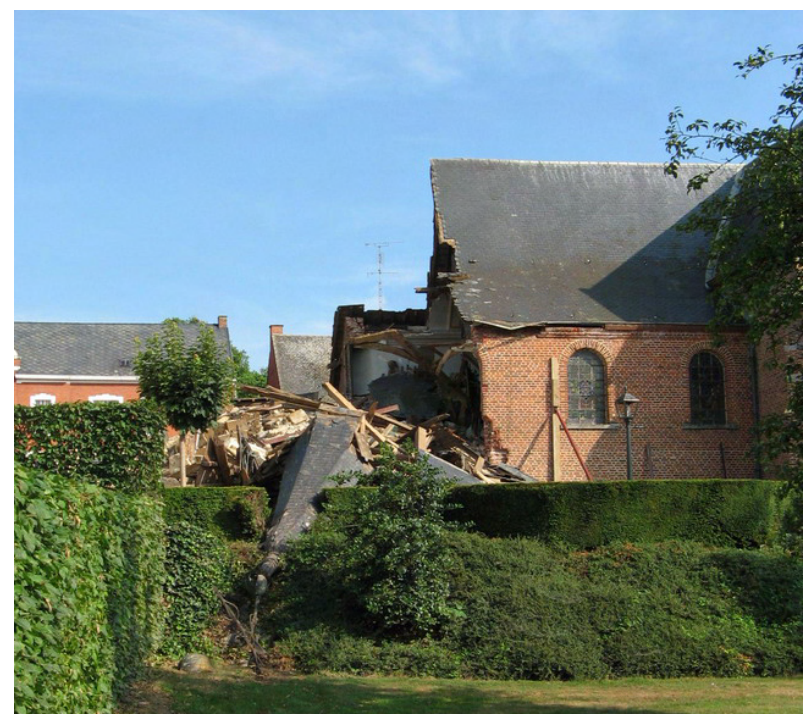

Figure 14: The bell tower of the church at Meldert after collapse, part of the spire being visible on top of the debris 


\section{Future prospects and repair options}

As ferruginous Diestian sandstone was used to construct numerous monuments in the central region of Belgium, different projects and a study group were set up to analyse the past, present and future use of Diestian sandstone. The focus is on two major problems, which require different measures:

- The Diestian ferruginous sandstone is very sensitive to moisture cycles, crust formation and weathering in general. This causes damage in particular stones, in groups of stones or in full walls, depending on their orientation and exposure.

- As was indicated in this paper, the sandstone has low strength, high scatter on its properties and is sensitive to creep damage. This could lead to (partial) collapse of the monuments.

The availability of new, original sandstone material from exploitation sites would improve the situation and enable a number of restorations. However, detailed investigations have indicated that the (re-)opening of exploitation sites is a difficult task. Many of the older sites, used in the Middle Ages and some of them up to the beginning of the $20^{\text {th }}$ century (for restoration works), have little amounts of good quality stone, are filled with rubble from previous mining activity, are unreachable or have become part of residential areas. Additionally, the formerly used exploitation techniques included patience and much trial and error. It is documented that vast amounts of the sandstone did not have the quality to be used as building material and mining activities included the production of large amounts of waste material [21]. The largescale, maximum-output techniques used in present days are not adapted to 
the problem at hand.

A variety of possible solutions were/are under discussion to tackle this difficult issue. In order to deal with surface damage, following solutions have been investigated:

- The use of stone consolidants was studied. For Diestian sandstone, consolidants such as ethyl silicate have most effect on good quality stones and are only effective for a restricted depth [22]. They could be a solution for weathering influences, but not for stones which are already severely damaged. Neither are they applicable to prevent creep damage.

- Repair mortars are under investigation. Encountered difficulties are: obtaining the right colour, compatibility with the old material concerning strength and stiffness, but also regarding moisture transport. Repair mortars often have restricted durability as the added material is easily loosened from the original stone due to temperature and moisture cycles.

Following interventions can been seen as possible solutions for structural problems concerning long-term structural behaviour of Diestian ferruginous sandstone:

- The damaged Diestian sandstone blocks are often replaced by Brusselian sandstone, which is a comparable material with better durability (more cohesive) and quality, but which has a different brown-purple colour, see Fig. 15. This option is a rather expensive solution as the 
availability of Brusselian sandstone is also limited. Unlike Diestian sandstone, the Brusselian sandstone does not contain glauconite. Brusselian ferruginous sandstone is coarser-grained and has a more homogeneous grain size distribution and a much faster capillary absorption [23]. A comparison between Brusselian and Diestian ferruginous sandstone is given in Table 3. The data are a summary of the results of experimental work carried out by Van Campenhout [23] on samples taken from 10 different sites ( 7 for Diestian and 3 for Brusselian ferruginous sandstone). The scatter on the test results is rather large and there's no marked distinction between the two sandstone types for the indicated characteristics. The average quality of the sandstone in this study appears to be better than the ferruginous sandstone samples from Meldert which were discussed in this paper, see Section 2.

Table 3: Comparison between Diestian and Brusselian ferruginous sandstone. Data summarised from [23] and indicated as average (coefficient of variation; number of samples)

\begin{tabular}{lcc}
\hline ferruginous sandstone type & Diestian & Brusselian \\
porosity $($ volume \%) & $28.4(9 \% ; 9)$ & $27.4(7 \% ; 3)$ \\
density $\left(\mathrm{kg} / \mathrm{m}^{3}\right)$ & $2070(5 \% ; 9)$ & $1957(4 \% ; 3)$ \\
compressive strength $(\mathrm{MPa})$ & $13(61 \% ; 9)$ & $7(62 \% ; 3)$ \\
\hline
\end{tabular}

- It was proposed to fabricate a type of imitation sandstone, using crushed sandstone as one of the components. This option has not yet been discussed, as it is unappealing from a "preservation of original material" [24] point of view and has to be approached carefully from technical point of view to preserve maximum compatibility with the original material. 


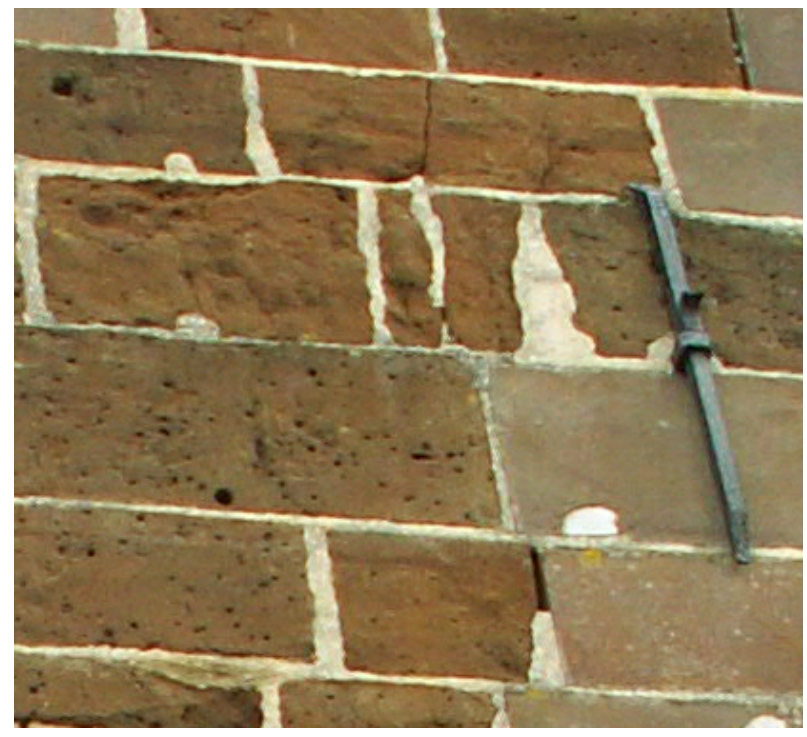

Figure 15: Diestian (dark brown, damaged stones) and Brusselian (purple stones in lower right corner) ferruginous sandstone. Picture taken at bell tower of church at Meldert before collapse

- Grout injection is a general solution to increase the masonry's strength and coherence. Main issues are the compatibility between the grout and the original material and the fact that a lot of water is injected in the masonry, which has a temporary negative effect on the masonry's stability. If no precautions are taken during the injection and hardening period, this can cause instabilities and (local) collapse. As an example, Fig. 16 shows pictures from grout injections carried out to strengthen the remaining structure of the partially collapsed Maagden tower at Zichem [16]. To test the compatibility and injectability of the grout, test injections with three different grout types have been carried out and core drilling has been applied to identify the most suited grout. All grout types used were commercially available grouts which had not 
been composed specifically for use in ferruginous sandstone.

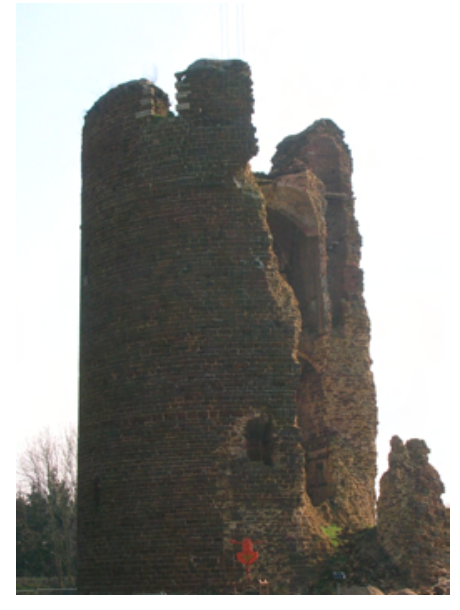

(a)

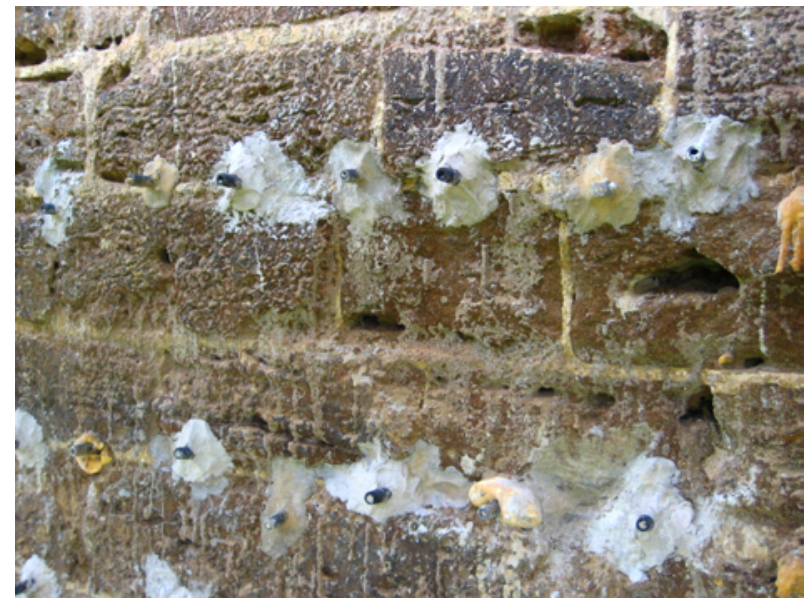

(b)

Figure 16: Partially collapsed Maagden tower at Zichem (a) and injection works to strengthen the remaining part of the tower (b)

- Some monuments constructed with ferruginous sandstone still show traces of older layers of plaster which were applied to protect the sandstone from weathering influences. This protective layer would also have had a positive influence on the structural behaviour of the masonry, as it prevented moisture ingress and deterioration of the mortar and sandstone itself. The (re-)application of such white plastering layers would completely alter the current appearance of monuments, constructed in dark-brown Diestian ferruginous sandstone. In Fig. 17, traces of an old plastering can be observed on the façade of the St. Catharina church at Diest (Belgium). The plaster is composed of hydrated lime, gypsum and quartz sand, without hydraulic components.

- Other case-specific strengthening techniques are possible, such as con- 


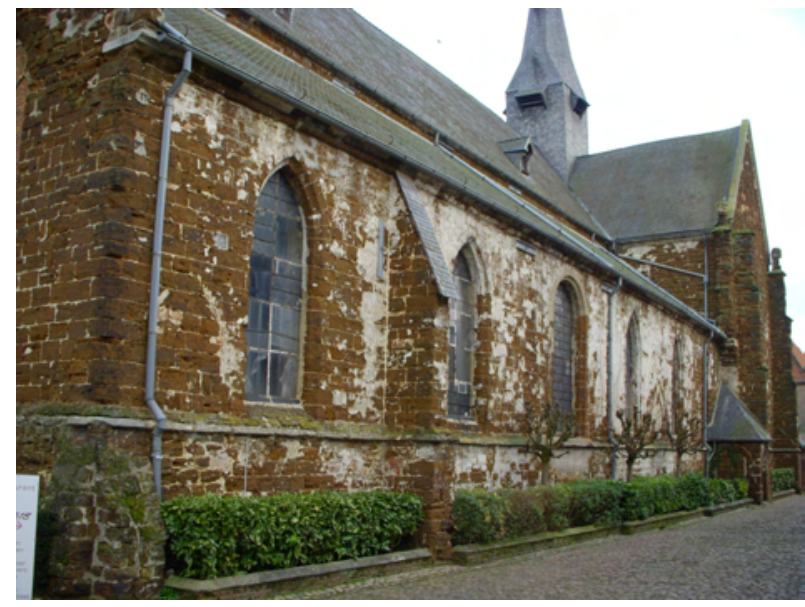

Figure 17: Traces of old plastering on Diestian ferruginous sandstone at the St. Catharina church at Diest (Belgium)

finement of the masonry. This intervention is easily applicable for columns and can be executed as a temporary measure (for example during grout injections). The lateral forces of the confinement increase the load bearing capacity of the column.

\section{Conclusions}

The stability assessment of historical structures, built with lower quality natural stones, is a complex problem. For the case of Diestian ferruginous sandstone, detailed studies were carried out to specify the material behaviour and describe the long-term effects of high sustained loading. These revealed very poor strength characteristics and sensitivity of the sandstone to timedependent mechanical deteriorations. With a 3D rheological creep model, calibrated on experimental results, the behaviour of the bell tower of the collapsed church at Meldert was simulated. The analysis indicated creep 
damage, however, additional effects, such as stress redistributions in threeleaf masonry and loss of inner cohesion of the masonry walls, need to be taken into account to get a more accurate description.

The lack of new, original sandstone material from exploitation sites complicates restoration of the numerous monuments built with ferruginous Diestian sandstone. For many monuments, case specific solutions are necessary which demand a thorough investigation and monitoring of the damage patterns, to obtain an accurate description of the damage state and damage accumulation.

\section{Acknowledgements}

The authors express their thanks to the Research Foundation - Flanders (FWO) for the doctoral grant, offered to Els Verstrynge.

\section{References}

[1] F. Gullentops, L'origine des collines du Hageland (in French), Bulletin de la Société Belge de géologie / Bulletin van de Belgische vereniging voor geologie 66 (1957) 81-85.

[2] K. Bos, F. Gullentops, Ijzerzandsteen als bouwsteen in en rond het Hageland (in Dutch), Bulletin de la Société Belge de géologie / Bulletin van de Belgische vereniging voor geologie 99 (2) (1990) 131-151.

[3] E. Verstrynge, L. Schueremans, D. Van Gemert, M. Wevers, Monitoring and predicting masonry's creep failure with the acoustic emission technique, NdtE International 42 (6) (2009) 518-523. 
[4] L. Binda, Learning from Failure - Long-term behaviour of heavy masonry structures, Vol. 23 of Advances in Architecture, WIT Press, Southampton, 2008.

[5] EN1990:2002, Eurocode - grondslag voor constructief ontwerp - Basis of structural design (July 2002).

[6] L. Schueremans, Probabilistic evaluation of structural unreinforced masonry, Phd thesis, Civil Engineering Department, K.U.Leuven (2001).

[7] M. Stewart, S. Lawrence, Model error, structural reliability and partial safety factors for structural masonry in compression, Masonry International 20 (3) (2007) 107-116.

[8] B. Ellingwood, Analysis of reliability for masonry structures, Journal of the Structural Division-Asce 107 (5) (1981) 757-773.

[9] L. Binda, A. Anzani, The time-dependent behaviour of masonry prisms: an interpretation, The Masonry Society Journal 11 (2) (1993) 570-587.

[10] L. Binda, L. Schueremans, E. Verstrynge, S. Ignoul, D. Oliveira, P. Lourenco, C. Modena, Long term compressive testing of masonry - test procedure and practical experience, in: D. D'Ayala, E. Fodde (Eds.), 6th International Seminar on Structural Analysis of Historical Constructions, Bath, 2008, pp. 1345-1355.

[11] E. Verstrynge, Long-term behaviour of monumental masonry constructions: modelling and probabilistic evaluation, Phd thesis, Civil Engineering Department, K.U.Leuven (2010). 
[12] A. Anzani, L. Binda, G. Roberti, The effect of heavy persistent actions into the behaviour of ancient masonry, Materials and Structures 33 (228) (2000) 251-261.

[13] E. Papa, A. Taliercio, A visco-damage model for brittle materials under monotonic and sustained stresses, International Journal for Numerical and Analytical Methods in Geomechanics 29 (3) (2005) 287-310.

[14] G. Boukharov, M. Chanda, N. Boukharov, The three processes of brittle crystalline rock creep, International Journal of Rock Mechanics and Mining Sciences and Geomechanics Abstracts 32 (4) (1995) 325-335.

[15] E. Verstrynge, L. Schueremans, D. Van Gemert, Time-dependent mechanical behavior of lime-mortar masonry, Materials and Structures 44 (1) (2010) 29-42.

[16] E. Verstrynge, L. Schueremans, D. Van Gemert, M. Hendriks, Modelling and analysis of time-dependent behaviour of historical masonry under high stress levels, Engineering Structures 33 (1) (2011) 210-217.

[17] Z. Bažant, B. Oh, Crack band theory for fracture of concrete, Materials and Structures 16 (93) (1983) 155-177.

[18] Z. Bažant, G. Pijaudier-Cabot, Nonlocal continuum damage, localization instability and convergence, Journal of Applied MechanicsTransactions of the Asme 55 (2) (1988) 287-293.

[19] M. Ramalho, A. Taliercio, A. Anzani, L. Binda, E. Papa, A numerical model for the description of the nonlinear behaviour of multi-leaf masonry walls, Advances in Engineering Software 39 (4) (2008) 249-257. 
[20] R. de Borst, L. Sluys, H.-B. Mühlhaus, J. Pamin, Fundamental issues in finite element analyses of localization of deformation, Engineering Computations 10 (1993) 99-121.

[21] RLNH vzw, Groeves met een ijzer-sterk verhaal (in Dutch), Aarschot, Belgium, 2007.

[22] H. De Clercq, R. Hayen, M. Dusar, The maagdentoren of zichem (belgium): Damage assessment of ferruginous sandstone and strengthening effect of consolidation with ethyl silicate (teos), in: 8th International Symposium on the Conservation of Monuments in the Mediteranean Basin, Patras, 2010.

[23] D. Van Campenhout, Verleden en toekomst van de exploitatie van ijzerzandsteen uit het diestiaan als bouwsteen, een geologische studie (in dutch), Msc thesis, Earth and Environmental Sciences Department, KULeuven (2009).

[24] The Venice Charter, international charter for the conservation and restoration of monuments and sites, P. Gazzola, www.icomos.org. 